\title{
Celebrating 125 years of Alpine Botany
}

\author{
Jürg Stöcklin ${ }^{1}$ - Rolf Holderegger ${ }^{2}$
}

(C) Swiss Botanical Society 2016

Alpine Botany has been edited by the Swiss Botanical Society since 1891 when the Society was founded. The first president of the society was Carl Schröter, an internationally renowned professor of botany at the ETH Zürich, Switzerland, who published his famous work on the flora of the Alps (Das Pflanzenleben der Alpen) in 1908. Editing a scientific journal was one of the most prominent activities of the new society. Botanical studies on alpine plants and vegetation had a prominent place from the beginning. No doubt, Alpine Botany has a prestigious tradition and is among the oldest scientific journals of the world. For 90 years the journal appeared as Berichte der Schweizerischen Botanischen Gesellschaft/Bulletin de la Société Botanique Suisse, in 1981 its name changed to Botanica Helvetica. In 2011, the Swiss Botanical Society relaunched the journal as Alpine Botany, now with the clear focus to provide an international forum for studies with a particular interest in plant ecology, vegetation and flora of alpine and mountain regions worldwide.

Of course, the character of the journal has changed a lot within the 125 years of its existence. At the beginning, the yearly society reports, protocols of annual meetings, treasury reports, and even membership lists were published together with scientific articles. After the First World War, high costs did not allow that society administrative reports were published any longer, and the journal became an exclusively scientific one. As long as the journal appeared as Berichte der Schweizerischen Botanischen Gesellschaft/ Bulletin de la Société Botanique Suisse, the content was

Jürg Stöcklin

juerg.stoecklin@unibas.ch

1 Institute of Botany, University of Basel, Schönbeinstrasse 6, 4056 Basel, Switzerland

2 Swiss Federal Research Institute WSL, Zürcherstrasse 111, 8903 Birmensdorf, Switzerland written either in German or French, the two most important languages of Switzerland. When the journal became Botanica Helvetica in 1981, articles were also partly written in English, the journal became more international-but still two-thirds of the authors came from Switzerland-and articles in German and French were dominant. Articles on topics such as systematics, vegetation science and ecology became more important from 1981 onwards, while articles with physiological, biochemical, mycological and phytopathological content became less frequent.

In 1997, ISI (Institute on Scientific Information) started to calculate and publish the Impact Factor (IF) of scientific journals. The IF of Botanica Helvetica varied then between 0.6 and 0.7 until 2006, and was in the mid-range of botanical journals. But then it slowly started to decline. Efforts were made to improve the journal, which culminated in re-launching the journal as Alpine Botany with an enlarged editorial board in 2011. Fortunately, the quality of submission has improved and the journal became fully international. The journal has strengthened its link with research on plants, vegetation and flora of alpine regions and now consequently aims at contributions that explore biological phenomena to understand functionally ongoing ecological, evolutionary and physiological processes. We are very thankful for financial support by the Swiss Academy of Sciences, which allows the Swiss Botanical Society to publish this journal. Currently, the IF of Alpine Botany is at 1.645, and its rank among plant journals worldwide has considerably ameliorated in recent years. We are proud on what has been achieved in the 125 years of existence of the journal, and we consider these achievements as an incentive and commitment to keep the level of Alpine Botany at a high level and to further improve it in the future.

Jürg Stöcklin (Editor in Chief of Alpine Botany)

Rolf Holderegger (President of the Swiss Botanical Society) 